\section{Rationing healthcare in South Africa: Renal replacement therapy - a case in point}

To the Editor: The South African Dialysis and Transplant Registry issued its last report on renal replacement therapy (RRT) in South Africa (SA) in 1994, followed by an unfortunate hiatus for 20 years. The recent publication of the long-awaited South African Renal Registry Annual Report 2012 should be highly commended. ${ }^{[1]}$ The private sector deserves to be acknowledged for its financial support of this initiative. Since 1994, the SA population has increased from 40.436 million to 52.275 million and the treatment rate for end-stage renal disease (ESRD) per million population (pmp) has improved from $70 \mathrm{pmp}$ in 1994 to $164 \mathrm{pmp}$ in $2012 .^{[1]}$ The treatment rate in 2012 for the public sector is essentially unchanged at $73 \mathrm{pmp}$, compared with $620 \mathrm{pmp}$ (of insured persons) in the private sector. In contrast, the low national kidney transplant rate of $4.7 \mathrm{pmp}$ highlights the dire need for organs. ${ }^{[1]}$

Between 1994 and 2012, the number of public sector treatment centres offering dialysis increased from 26 to 28 , while in the private sector there was an increase from 5 to $163{ }^{[1]}$ There has been a population-appropriate change in the relative representation of different ethnic groups, with a $64 \%$ increase in black patients accessing RRT since 1994 and a drop of $50 \%$ in white patients. There are still two provinces in SA - Limpopo and Mpumalanga - with no public dialysis facility.

The annual increase in people requiring RRT worldwide is estimated to be $8 \%$, which is far in excess of the global population growth rate of $1.3 \% .{ }^{[2]}$ In the light of a large chronic disease burden in SA, contributed to by both communicable and non-communicable diseases, with chronic kidney disease arising largely from diabetes, hypertension, obesity and $\mathrm{HIV},{ }^{[3]}$ an increase in RRT services beyond $8 \%$ is required.

In 2006, Professor M R Moosa of Tygerberg Academic Hospital (TAH), Cape Town, stated: 'In 1997, the funding of our dialysis unit was capped to allow treatment of 80 patients with [ESRD] and has remained unchanged since. ${ }^{\left[{ }^{[4]}\right.}$ He showed that $52 \%$ of ESRD patients are denied RRT treatment at $\mathrm{TAH}^{[4]}$ Despite ongoing rationing without review and the subsequent denial of treatment, there is very little public awareness and debate around the rationing process and policy that regulates patient access to RRT. There is also no independent body that reviews the medical ethics of rationing in the public sector (which is often centre-specific).

Kidney transplant rates remain low. In 2012, there were no kidney transplants performed in public sector centres in either Free State or KwaZulu-Natal provinces. In Gauteng and the Western Cape, 22 and 21 kidney transplants, respectively, were performed at public sector transplant units. Of the 110 adult cadaveric kidney transplants done in 2012, 43 (39.1\%) were in the public sector. The discrepancy between private and public sector transplant rates and regional differences in transplant activity highlight the complexity around organ procurement, organ allocation and transplantation in different regions, which is a separate, complex debate.

In the light of the registry data, the government needs to be made aware of these figures for planning and service provision in the public sector. The Minister of Health, Dr Aaron Motsoaledi, has met with Prof. Razeen Davids, first author of the South African Renal Registry Annual Report 2012, ${ }^{[1]}$ to discuss the data. He has constructively suggested a summit later this year to discuss chronic/ ESRD management strategies.

\section{June Fabian \\ Department of Internal Medicine, Faculty of Health Sciences, University of the Witwatersrand, Johannesburg, South Africa, and Research Unit, Wits Donald Gordon Medical Centre, Johannesburg june.fabian@mweb.co.za}

\section{Russell Britz}

Head of the Division of Transplantation Surgery, Charlotte Maxeke Johannesburg Academic Hospital, South Africa, Department of Surgery, Faculty of Health Sciences, University of the Witwatersrand, Johannesburg, and Wits Donald Gordon Medical Centre, Johannesburg

\section{Anna Sparaco}

Division of Transplantation Surgery, Charlotte Maxeke Johannesburg Academic Hospital, South Africa, Faculty of Health Sciences, University of the Witwatersrand, Johannesburg, and Wits Donald Gordon Medical Centre, Johannesburg

\section{Shoyab Wadee}

Nephrologist in private practice, Wits Donald Gordon Medical Centre, Johannesburg, South Africa

\section{Errol Gottlich}

Paediatric nephrologist in private practice, Morningside Mediclinic, Johannesburg, South Africa

\section{Tina Sideris}

Clinical Psychologist, Wits Donald Gordon Medical Centre, Johannesburg, South Africa

\footnotetext{
1. Davids M, Marais N, Jacobs J. South African Renal Registry Annual Report 2012. Cape Town: South African Renal Society, 2014.

2. Schieppati A, Remuzzi G. Chronic renal diseases as a public health problem: Epidemiology, social, an economic implications. Kidney Int Suppl 2005;68(Suppl 98):S7-S10.

3. Mayosi BM, Flisher AJ, Lalloo UG, Sitas F, Tollman SM, Bradshaw D. The burden of noncommunicable diseases in South Africa. Lancet 2009;374(9693):934-947. [http://dx.doi.org/10.1016/ S0140-6736(09)61087-4]

4. Moosa MR, Kidd M. The dangers of rationing dialysis treatment: The dilemma facing a developing country. Kidney Int 2006;70(6):1107-1114.
}

S Afr Med J 2014;104(9):593. DOI:10.7196/SAMJ.8559 